\title{
Long-Term Persistence of Specific Genetic Types of Mastitis-Causing Staphylococcus aureus on Three Dairies
}

\author{
K. L. Anderson ${ }^{1}$ and R. L. Lyman \\ Department of Population Health \& Pathobiology, College of Veterinary Medicine, North Carolina State University, \\ 4700 Hillsborough Street, Raleigh 27606
}

\begin{abstract}
Pulsed-field gel electrophoresis (PFGE) after SmaI digestion was used to investigate the persistence of specific genotypes of bovine mammary gland isolates of Staphylococcus aureus on 3 dairy herds. A total of 341 isolates of Staph. aureus were available from cows in 3 herds, collected over a period of $15 \mathrm{yr}$. Pulsed-field gel electrophoresis band patterns of Staph. aureus isolates were analyzed visually and with gel analysis and comparison software. Based on this analysis, isolates were classified by PFGE type. Persistence was determined as the time period from the first to the last isolation of a particular PFGE type of Staph. aureus within a herd. Specific types of mastitis-causing Staph. aureus persisted long-term on these dairies. For example, PFGE type 3 isolates persisted on farms $\mathrm{A}, \mathrm{B}$, and $\mathrm{C}$ for 15 , 15 , and $13 \mathrm{yr}$, respectively. Type 6 was found to persist for $13 \mathrm{yr}$ on farm C. Despite the application of standard mastitis control practices, mastitis-causing Staph. aureus types appeared to persist long-term, as detected by PFGE, and were isolated coincident with herd problems of increased milk somatic cell counts and decreased milk production.
\end{abstract}

Key words: mastitis, Staphylococcus aureus, persistence, genotype

\section{INTRODUCTION}

Staphylococcus aureus remains a common and an economically significant cause of mastitis in dairy cattle. This is despite the current application of control methods for Staph. aureus mastitis. A variety of molecular approaches have been used to investigate the epidemiology of Staph. aureus mastitis in search of improved treatment and control. Clones (or types or strains or pulsotypes) of Staph. aureus have been described and investigated with respect to molecular characteristics or behavior, or both. Most of the studies of

Received December 18, 2005.

Accepted May 26, 2006.

${ }^{1}$ Corresponding author: kevin_anderson@ncsu.edu mastitis-causing Staph. aureus have found that a given herd usually harbors a limited number of Staph. aureus strains, often with one or a few strains predominating in those herds with multiple strains (Matthews et al., 1994; Kapur et al., 1995; Fitzgerald et al., 1997; Larsen et al., 2000; Buzzola et al., 2001; Sommerhäuser et al., 2003; Mørk et al., 2005; Rabello et al., 2005). It has been suggested that control of mastitis should be focused on the specific strains of Staph. aureus causing infection in a given herd (Kapur et al., 1995).

Few studies have examined the longevity or "persistence" of strains of Staph. aureus within a herd. Aarestrup et al. (1995) used ribo- and phage-typing to compare Staph. aureus isolates from different farms in Denmark from 1952 to $1956(\mathrm{n}=23)$ with isolates from $1992(\mathrm{n}=29)$. They found that 3 dominant types persisted for about $40 \mathrm{yr}$ on farms in Denmark, but did not present any information on the persistence of predominant types on specific farms. Raimundo et al. (1999) reported that cows chronically infected with Staph. aureus demonstrated persistence of a single PCR type of Staph. aureus for periods of up to 9 mo. A total of 404 Staph. aureus isolates from IMI from 9 dairy herds in Denmark were followed during a 1.5- to 2-yr period (Larsen et al., 2000). Larsen et al. (2000) found that there was only limited diversity of "types" within herds, that some given strain(s) would persist in a herd for 1.5 to $2 \mathrm{yr}$, and that some strains appeared to spread more easily and persist longer than other strains.

Buzzola et al. (2001) studied 112 isolates of Staph. aureus from the milk of cows with clinical mastitis in 21 districts in Argentina. When isolates were categorized by a combination of ribo- and pulsed-field gel electrophoresis (PFGE)-type, 2 of the most prevalent "strains," A/I and A11/VI, were found to persist in samples from the Argentinean dairies during the $8 \mathrm{yr}$ studied. At least one study in humans indicated that a clone of methicillin-resistant Staph. aureus (MRSA) persisted long-term in an Australian human hospital (Givney et al., 1998).

Beginning in 1998, we identified herd problems of elevated bulk milk SCC caused by Staph. aureus in 2 dairy herds. The herds involved were owned and operated by the same organization, and cows had moved to 
Table 1. Staphylococcus aureus isolates by year, pulsed-field gel electrophoresis type, and farm

\begin{tabular}{|c|c|c|c|c|c|c|c|c|c|c|c|c|c|c|c|}
\hline \multirow[b]{3}{*}{ Year } & \multicolumn{14}{|c|}{ PFGE type } & \multirow[b]{3}{*}{ Total } \\
\hline & \multicolumn{6}{|c|}{ Farm A } & \multicolumn{4}{|c|}{ Farm B } & \multicolumn{4}{|c|}{ Farm C } & \\
\hline & 1 & 2 & 3 & 6 & 7 & Subtotal & 2 & 3 & 27 & Subtotal & 2 & 3 & 6 & Subtotal & \\
\hline 1988 & & & 11 & & 10 & & & 3 & & & & 2 & 1 & & 27 \\
\hline 1990 & & & 1 & & 1 & & & & & & & & & & 2 \\
\hline 1991 & & & & & & & 1 & & & & & & & & 1 \\
\hline 1993 & & & 7 & & & & 4 & 5 & & & 3 & & 1 & & 20 \\
\hline 1996 & & & & & & & & & & & & & 1 & & 1 \\
\hline 1998 & 40 & 7 & 4 & 3 & & & & & & & & 1 & & & 55 \\
\hline 1999 & 3 & 12 & 4 & 2 & & & & & & & & & & & 21 \\
\hline 2000 & 3 & 3 & 3 & 3 & & & 49 & 2 & & & & & & & 63 \\
\hline 2001 & 3 & 9 & 2 & 2 & & & 67 & & & & 3 & 3 & 1 & & 90 \\
\hline 2002 & & 1 & 8 & & & & 16 & 5 & 1 & & & & & & 31 \\
\hline 2003 & & 2 & 3 & 4 & & & 17 & 4 & & & & & & & 30 \\
\hline Total & 49 & 34 & 43 & 14 & 11 & 151 & 154 & 19 & 1 & 174 & 6 & 6 & 4 & 16 & 341 \\
\hline
\end{tabular}

a limited degree between the herds. We had worked with these herds over a long period of time and had isolates stored frozen at $-75^{\circ} \mathrm{C}$ from these herds and from a third dairy owned and operated by the same organization. Because of this, we chose to study the genetic relatedness of the Staph. aureus isolated from the 3 herds, as well as the persistence of given strains on a particular dairy.

The objective was to examine PFGE band patterns of isolates of Staph. aureus collected over $15 \mathrm{yr}$ and to analyze their presence both within and among the 3 dairy herds. We hypothesized that a given genotype of Staph. aureus would remain within a herd for only a limited period of time.

\section{MATERIALS AND METHODS}

\section{Milk Samples}

All milk samples producing isolates of Staph. aureus were quarter or composite milk samples submitted to the Mastitis and Milk Microbiology Laboratory at the College of Veterinary Medicine for the purpose of mastitis diagnostics. Samples were available for this investigation from 2 major sources. The first was from investigation of the problems in the herds presented here. A second source was Staph. aureus isolates that had been obtained from milk samples from the respective herds prior to investigation of the mastitis problems described. Starting in 1988, some mastitis diagnostics had been performed in the herds at intervals, and isolates of Staph. aureus or milk samples had been saved frozen at -70 to $-80^{\circ} \mathrm{C}$ in some instances. The number of isolates by herd is given in Table 1 .

\section{Herd Histories}

Herds A, B, and C and Cow Movement. All 3 herds practiced mastitis control programs consistent with those established by the National Mastitis Council, current at the time of consideration. This included consistent use of postmilking teat dipping, dry-cow therapy, milking machine maintenance, and proper milking procedures. Selection of antimicrobial drugs used for lactating and dry-cow intramammary therapy was based on antimicrobial susceptibility testing done on an asneeded basis. All herds were milked in parlors twice a day. Cows were fed a TMR composed of grain concentrate, corn silage, and minerals, with access to hay. Beginning in 1998, herd A made a transition to a pasture-based management system.

The only movement documented among the herds during the period of study was transfer of approximately 60 to 70 milking cows from herd $\mathrm{C}$ to herd $\mathrm{A}$ in 1997 to 1998 and movement of 10 lactating cows from herd $\mathrm{C}$ to herd $\mathrm{B}$ in 2001 . The only known new additions introduced to the herds were 24 purchased cross-bred cows introduced into herd A in May of 1998. Milk cultures were not performed prior to or coincident with introduction of these cows to herd A.

Herd A. In early 1998, herd A experienced an increase in bulk tank milk SCC to levels above 1 million cells/mL, with decreased milk production. Herd A consisted of 150 to 180 lactating Holstein cows during the period between March and September of 1998. The herd had been moved from an older parlor facility to a new parlor during the period from December of 1997 to January of 1998. Dairy Herd Improvement Association testing was conducted, but had not been done between March and September of 1998 because of the transition to new facilities and incompatibilities with testing equipment. During this period, DHIA testing indicated cows were producing between 13.6 and $21.4 \mathrm{~kg}$ of milk/ head per $\mathrm{d}$ and weighted average actual SCC ranged from $737,000 / \mathrm{mL}$, to $1,101,000 / \mathrm{mL}$.

Microbiological analysis conducted in mid-1998 on a bulk tank milk sample revealed a total bacterial count 
of $6,940 \mathrm{cfu} / \mathrm{mL}$, with $3,000 \mathrm{cfu} / \mathrm{mL}$ of Staph. aureus. Further culturing of milk samples from individual cows indicated that approximately one-third of milking cows in the herd had Staph. aureus IMI.

Herd B. In 2000, a second dairy herd (B) showed increased SCC and decreased milk production. This herd consisted of approximately 100 lactating Holstein cows. Weighted average SCC had ranged from 591,000/ $\mathrm{mL}$ to $901,000 / \mathrm{mL}$ over the previous $12 \mathrm{mo}$, with a mean of 752,000 cells $/ \mathrm{mL}$. Milk production ranged from 19.1 to $27.8 \mathrm{~kg} / \mathrm{cow}$ per d, with a mean of $24.1 \mathrm{~kg} /$ cow per d.

A bulk tank milk sample collected in July of 2000 revealed a total bacterial count of $2,800 \mathrm{cfu} / \mathrm{mL}$, with $700 \mathrm{cfu} / \mathrm{mL}$ of Staph. aureus. A whole-herd culture of composite milk samples from 101 cows in July of 2000 revealed 51:101 (53.5\%) of cows culturing positive for Staph. aureus.

Herd C. This herd consisted of 220 to 250 lactating Holstein cows. The herd had not experienced a specific mastitis or SCC problem. A minimum number of isolates of Staph. aureus were available from the herd. Rolling herd average milk varied from 9,545 to 10,455 $\mathrm{kg}$ of milk/cow from 1997 to 2003, with the average being consistently $\geq 10,455 \mathrm{~kg}$ after 2000 . Weighted average $\mathrm{SCC} / \mathrm{mL}$ were $312,000,376,000,294,000,372,000$ and 485,000 in 1999, 2000, 2001, 2002, and 2003, respectively. Milk production in kilograms per cow per day was 28.8 in 1999, 26.4 in 2000, 29.2 in 2001, 29.3 in 2002 , and 29.2 in 2003.

\section{Microbiological Procedures}

Milk sample collection and culturing procedures were consistent with those described by the National Mastitis Council (Hogan et al., 1999). Freshly collected milk samples were refrigerated and were either plated within $24 \mathrm{~h}$ or frozen for no more than $1 \mathrm{wk}$ at $-20^{\circ} \mathrm{C}$. All stored samples were quick-thawed and plated as follows. Milk samples were vortexed and $0.01 \mathrm{~mL}$ of milk was plated on trypticase soy agar with $5 \%$ sheep blood (Becton, Dickinson and Co., Sparks, MD). In some cases, such as from clinical cases, $0.1 \mathrm{~mL}$ of milk was plated. Plates were incubated at $36^{\circ} \mathrm{C}$ and examined at 24 and 48 h. Creamy, grayish-white, or golden-yellow pigmented colonies that were catalase-positive and coagulase-positive gram-positive cocci and that exhibited complete, incomplete, or both complete and incomplete hemolysis were identified as Staph. aureus. Similar colonies with no hemolysis were confirmed as Staph. aureus using the API Staph identification system (bioMérieux Vitek, Inc., Hazelwood, MO). Either the original milk samples or pure cultures of Staph. aureus in trypticase soy broth with $15 \%$ glycerol, or both, were stored at -70 to $-80^{\circ} \mathrm{C}$.

\section{PFGE}

Preparation of bacterial DNA and digestion by $S m a \mathrm{I}$, as well as PFGE, were performed as previously described (Shimizu et al., 1996), with minor modifications described hereafter. DNA was prepared according to the methods of Shimizu et al. (1996), except that $5 \mu \mathrm{L}$, rather than $10 \mu \mathrm{L}$, of lysostaphin solution was added to the cell suspension, and $40 \mathrm{U}$, rather than $20 \mathrm{U}$, of SmaI was used. Digest fragments were separated using a CHEF-DR II Pulsed Field Electrophoresis System (Bio-Rad Laboratories, Inc., Hercules, CA) with a pulse increase of 15 to $55 \mathrm{~s}$ at $200 \mathrm{~V}$ for $22 \mathrm{~h}$ at $14^{\circ} \mathrm{C}$. The gels were stained in a $0.1 \%$ ethidium bromide solution for $15 \mathrm{~min}$ and destained in distilled water for $2 \mathrm{~h}$.

Stained gels were photographed with a Polaroid MP-4 Land Camera (Polaroid Corporation, Cambridge, MA), and the photographs were scanned into a computer. The scanned photographs were processed, and dendrograms were made using gel analysis and comparison software (BioNumerics; Applied Maths, Inc., Austin, TX). Similarity coefficients were calculated, and dendrograms were constructed using the Dice coefficient and the unweighted pair group method with arithmetic averages, respectively, with an optimization value of $0.50 \%$ and a position tolerance of $1.0 \%$ (Applied Maths, 2000).

\section{Definitions of PFGE Pattern and Type}

Interpretation of electrophoretic patterns was consistent with that of Tenover et al. (1995), with modifications. Isolates were considered to have the same PFGE pattern if PFGE band patterns were identical. The first pattern encountered was considered to be type pattern 1 and was used to compare with new banding patterns. Isolates with $\leq 6$ band differences from the type pattern were considered to be the same type. The first pattern that differed from type pattern 1 by $>6$ bands was considered type pattern 2, and so on. Coincidentally, in this data set, type patterns were those PFGE patterns that had the greatest number of isolates within the type (numbers 2, 10, 29, and 38 in Figure 1). Based on this definition, individual types clustered above a similarity level of $80 \%$ on the dendrogram (Figure 1).

\section{Isolates Analyzed}

Only the first isolate per cow was used unless more than one PFGE pattern was found in milk from the same cow.

\section{Persistent Infections}

The persistence in years was determined within farm and on all farms by type and PFGE pattern. Persistence 


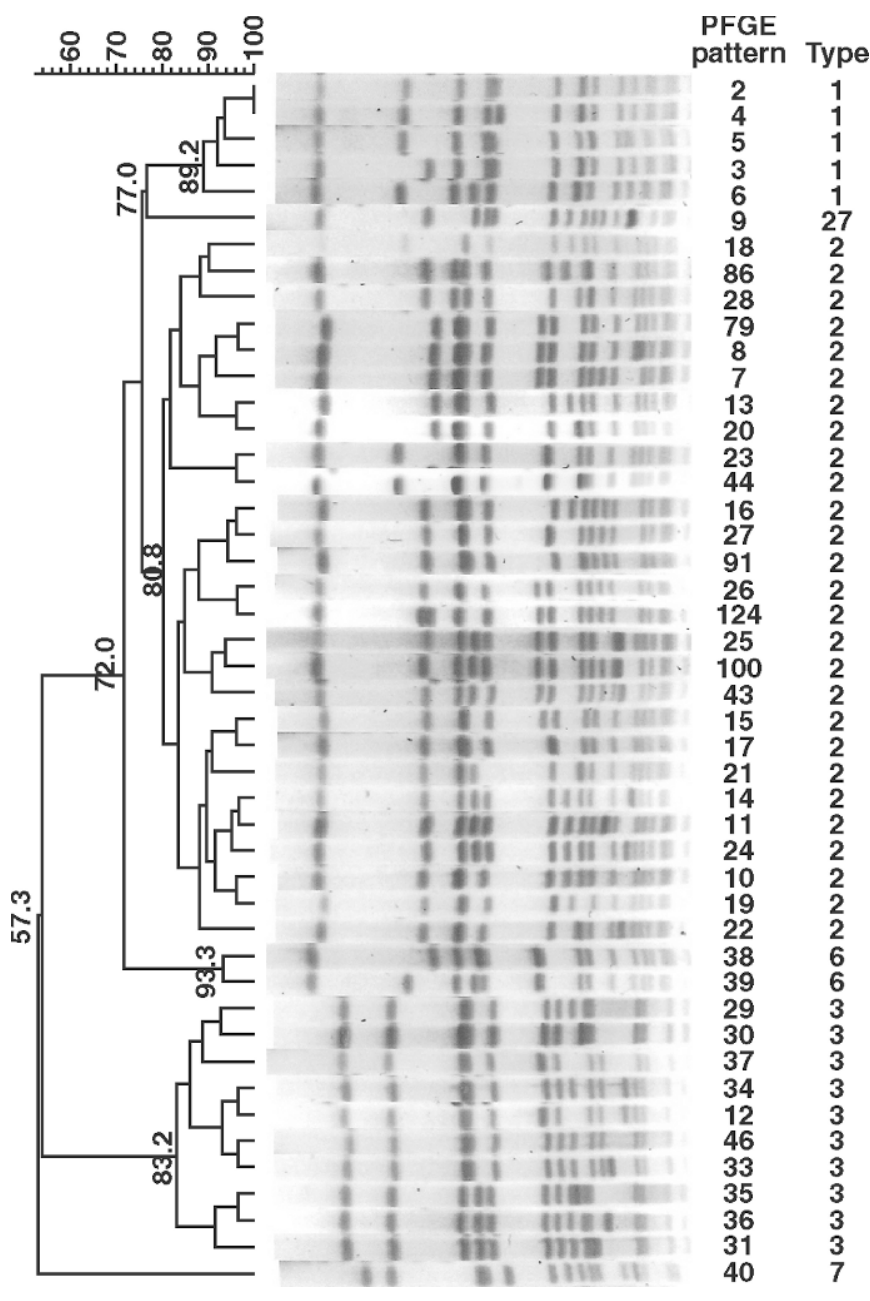

Figure 1. Composite gel of all pulsed-field gel electrophoresis (PFGE) patterns and types of Staphylococcus aureus isolates, and a dendrogram showing the relatedness of patterns.

was defined as the period of time in years, as measured in our study, between the first and last reported isolation of a specific type of PFGE pattern on a given farm. For all farms, persistence was defined as the period of time in years from first to last isolation of a specific type or PFGE pattern on any farm.

\section{RESULTS}

A total of 341 isolates of Staph. aureus were obtained from the 3 farms between February of 1988 and November of 2003 (see Table 1). For farms A, B, and C, a total of 151,174 , and 16 isolates of Staph. aureus, respectively, were available for investigation (Table 1).

Years of persistence of Staph. aureus by type for farms $\mathrm{A}, \mathrm{B}$, and $\mathrm{C}$ as well as for all farms are shown in Table 1. For farm A, type 7 was isolated only in early samples (1988 and 1990), but not after that time. Type
3 isolates were consistently isolated from farm A during all time periods with samples. Isolates of types 1,2 , and 6 were found in more recent years. Farm B demonstrated a predominance of isolates of types 2 and 3, with a single isolate of type 27 . Both types 2 and 3 were present on the farm long-term. Only a limited number of isolates were available from farm C. Isolates of both types 3 and 6 were present long-term, and type 2 isolates persisted reasonably long-term as well.

Table 1 gives persistence, in years, for types by farm and for all farms. Types 2 and 3 were common to all 3 farms. For farm A, persistence of types 2 and 3 was 5 and $15 \mathrm{yr}$, respectively. Types 1,6 , and 7 persisted for 3,5 , and $2 \mathrm{yr}$, respectively. For farm B, only types 2 , 3 , and 27 were present; types 2 and 3 persisted for 12 and $15 \mathrm{yr}$, respectively. For farm $\mathrm{C}$, types 2,3 , and 6 persisted for 8,13 , and $13 \mathrm{yr}$, respectively. Considering all farms, types 1, 2, 3, 6, and 7 persisted for $3,12,15$, 15 , and $2 \mathrm{yr}$, respectively.

Some specific PFGE patterns persisted unchanged for 10 or more years (numbers 10, 29, 30, 31, 36, and 38 in Figure 1). Pulsed-field gel electrophoresis pattern 29 persisted for 14,15 , and $13 \mathrm{yr}$, respectively, on farms $\mathrm{A}, \mathrm{B}$, and C, whereas PFGE patterns 10, 30, and 36 persisted for 10,11 , and $13 \mathrm{yr}$, respectively, on farms B, A, and A. Patterns 31 and 38 persisted for 14 and 15 yr over all farms.

\section{DISCUSSION}

Our study demonstrated that some PFGE-defined types of mastitis-causing Staph. aureus appeared capable of persisting long-term in a given dairy herd. Type 3 Staph. aureus isolates persisted on farms A, B, and $\mathrm{C}$ for 15,15 , and $13 \mathrm{yr}$, respectively, whereas type 6 Staph. aureus isolates were shown to persist on farm $\mathrm{C}$ for a period of $13 \mathrm{yr}$. Specific PFGE patterns were isolated unchanged for 10 to $15 \mathrm{yr}$. The apparent longterm persistence of specific patterns and PFGE-defined types of mastitis-causing Staph. aureus suggested that these types were quite stable and unlikely to undergo a major genetic change over prolonged time periods, as detected by PFGE.

Of interest is the repeated isolation of specific PFGE types of Staph. aureus from the herds studied here over an extended period of time. However, some limitations of the study should be noted. More frequent and systematic sampling would have been ideal to document the persistence of types within herds more conclusively. Also, the impact of the movement of cows as well as the introduction of new cows to one of the herds cannot be ruled out as a possible means of introduction or reintroduction of reportedly persistent types of Staph. aureus. 
Relatively little data are reported in the literature with which to compare these results. Aarestrup et al. (1995) investigated Staph. aureus isolates from Danish dairy farms using molecular techniques and found that defined types of Staph. aureus found between 1952 and 1956 were also present in 1992 . However, the study did not investigate whether the particular types persisted on a given dairy. Buzzola et al. (2001) reported that particular genotypes of mastitis-causing Staph. aureus persisted for a period of $8 \mathrm{yr}$ in Argentina, but did not investigate persistence on specific individual farms. Individual genotypes were found to persist in a specific dairy in Denmark for 1.5 to 2 yr (Larsen et al., 2000). Raimundo et al. (1999) found that a unique genotype of Staph. aureus could persist in an individual cow for up to 9 mo. A clone of MRSA has been reported to persist in a tertiary human referral hospital for a prolonged period (Givney et al., 1998). The results from the present study appear to be consistent with those of previous studies, demonstrating the possibility of apparent longterm persistence of Staph. aureus as a pathogen in some environments, specifically here as a cause of mastitis.

The recognition of the presence of persistent types of Staph. aureus leads one to question whether specific characteristics of these types favor persistence. There is evidence of variations in virulence or pathogenicity, or both, of individual strains of Staph. aureus. For example, Haveri et al. (2005) studied the relationship between strain type of Staph. aureus and pathogenicity using 217 Staph. aureus isolates from 116 dairy cows from Finland. They found a clear association between PFGE pulsotypes and severity of symptoms. One particular pulsotype, type B, was associated with severe symptoms and infections that were rapidly eliminated from affected quarters. Other pulsotypes produced infections that progressed more slowly and became chronic. Long-term persistence was associated with chronicity and less acute symptoms.

Zadoks et al. (2000) investigated 38 isolates of Staph. aureus collected from 8 dairy herds over a 2-yr period. Using PFGE and binary typing, they found associations between genotype and severity of the disease, suggesting strain-specific bacterial virulence. They did not specifically evaluate long-term persistence. Sommerhäuser et al. (2003) used phenotyping and genotyping methods to follow Staph. aureus in 7 herds during institution of a control program. Typing results and clinical observations indicated a difference in strains with respect to tendency to spread and ability to infect udders. In 3 herds, a predominant type was found with epidemiologic features of a contagious mastitis pathogen, whereas in other herds there was no predominant type and the behavior of the Staph. aureus was similar to an environmental pattern.
Another example of variation in biological behavior of mastitis-causing Staph. aureus is that of an outbreak of mastitis caused by emergence of a new strain of Staph. aureus in a herd with other known strains of Staph. aureus (Smith et al., 1998). This new strain spread within the herd and required different management strategies to decrease its presence in the herd (Middleton et al., 2001). The herds in our investigation all used standard mastitis control practices such as teat dipping, dry-cow therapy, and other components of recognized mastitis control programs. Despite this, selected types of Staph. aureus appeared to persist longterm in the herds. This suggests limitations of the control practices in controlling the particular persistent strains involved.

Multiple properties of Staph. aureus contribute to its virulence. Additionally, multiple mechanisms may contribute to persistence of infection. Using bovine epithelial cell lines, Bayles et al. (1998) demonstrated that a mastitis-causing strain of Staph. aureus, the Novel strain, became intracellular after contact with surfaces of the mammary epithelial cells. Once internalized, the bacteria escaped from the endosome, lived within the cell, and caused it to become apoptotic. Via an unconfirmed mechanism, this process appears to assist Staph. aureus in causing chronic infection of the mammary gland. Cucarella et al. (2004) demonstrated that biofilm-producing isolates of Staph. aureus from bovine mastitis were more likely to produce persistent infections.

Contrary to what we found in this study, it has been suggested that PFGE may have limitations in investigating the long-term epidemiology of Staph. aureus infections (Blanc et al., 2002). Blanc et al. (2002) assessed PFGE for its ability to investigate the long-term scale epidemiology (from years to a few decades) of MRSA (Blanc et al., 2002). A total of 20 strains of MRSA were investigated, most from a population genetic analysis of MRSA from France. The isolates were analyzed by multiprimer (10 primers) random amplification polymorphism DNA. Results were compared with PFGE (SmaI restriction) using large ( $>85-\mathrm{kb})$ and small (10to $85-\mathrm{kb}$ ) fragments. Pulsed-field gel electrophoresis analysis of small bands was found to correspond with results of random amplification polymorphism DNA analysis better than PFGE analysis of large bands. The authors indicated that large bands were subject to greater potential for genetic change. In our study, however, we found that specific types of mastitis-causing Staph. aureus appeared to persist long-term on a given dairy farm with minimal changes in bands, as detected by PFGE. 


\section{CONCLUSIONS}

Specific types of mastitis-causing Staph. aureus appeared to persist largely unchanged in these 3 herds for periods much longer than $10 \mathrm{yr}$. Two types were common to all 3 herds. These Staph. aureus types persisted despite application of standard mastitis control practices. Apparently persistent strains were isolated in association with herd problems of increased SCC and decreased milk production. Specific properties of the persistent strains most likely helped produce chronic, long-standing infections. Further investigation of these strains may add to an understanding of both the pathogenesis of persistent Staph. aureus mastitis and the microbial properties contributing to persistence.

\section{ACKNOWLEDGMENTS}

We acknowledge the assistance and contributions of the staff and management of the 3 participating dairy herds. We also acknowledge the assistance and contributions of former students in the College of Veterinary Medicine and the Merck-Merial Summer Research Program, including Chris Spooner and Paige Smith. Supported in part by the North Carolina Dairy Foundation, Inc. (Raleigh, NC), the state of North Carolina, and USDA Animal Health Funds.

\section{REFERENCES}

Aarestrup, F. M., H. C. Wegener, and V. T. Rosdahl. 1995. A comparative study of Staphylococcus aureus strains isolated from bovine subclinical mastitis during 1952-1956 and 1992. Acta Vet. Scand. 36:237-243

Applied Maths. 2000. BioNumerics: The Integral Study of Biological Relationships: Manual Version 2.5. Applied Maths, Inc., Austin, TX.

Bayles, K. W., C. A. Wesson, L. E. Liou, L. K. Fox, G. A. Bohach, and W. R. Trumble. 1998. Intracellular Staphylococcus aureus escapes the endosome and induces apoptosis in epithelial cells. Infect. Immun. 66:336-342.

Blanc, D. S., P. Francioli, and P. M. Hauser. 2002. Poor value of pulsed-field gel electrophoresis to investigate long-term scale epidemiology of methicillin-resistant Staphylococcus aureus. Infect. Genet. Evol. 2:145-148.

Buzzola, F. R., L. Quelle, M. I. Gomez, M. Catalano, L. Steele-Moore, D. Berg, E. Gentilini, G. Denamiel, and D. O. Sordelli. 2001. Genotypic analysis of Staphylococcus aureus from milk of dairy cows with mastitis in Argentina. Epidemiol. Infect. 126:445-452.

Cucarella, C., M. Á. Tormo, C. Úbeda, M. P. Trotonda, M. Monzón, C. Peris, B. Amorena, Í. Lasa, and J. R. Penadés. 2004. Role of biofilm-associated protein Bap in the pathogenesis of bovine Staphylococcus aureus. Infect. Immun. 72:2177-2185.

Fitzgerald, J. R., W. J. Meaney, P. J. Hartigan, C. J. Smyth, and V. Kapur. 1997. Fine-structure molecular epidemiological analysis of Staphylococcus aureus recovered from cows. Epidemiol. Infect. 119:261-269.

Givney, R., A. Vickery, A. Holliday, M. Pegler, and R. Benn. 1998. Evolution of an endemic methicillin-resistant Staphylococcus aureus population in an Australian hospital from 1967 to 1996. J. Clin. Microbiol. 36:552-556.

Haveri, M., S. Taponen, J. Vuopio-Varkila, S. Salmenlinna, and S. Pyörälä. 2005. Bacterial genotype affects the manifestation and persistence of bovine Staphylococcus aureus intramammary infection. J. Clin. Microbiol. 43:959-961.

Hogan, J. S., R. N. González, R. J. Harmon, S. C. Nickerson, S. P. Oliver, J. W. Pankey, and K. L. Smith. 1999. Laboratory Handbook on Bovine Mastitis. Rev. ed. The National Mastitis Council, Madison, WI.

Kapur, V., W. M. Sischo, R. S. Greer, T. S. Whittam, and J. M. Musser. 1995. Molecular population genetic analysis of Staphylococcus aureus recovered from cows. J. Clin. Microbiol. 33:376-380.

Larsen, H. D., K. H. Sloth, C. Elsberg, C. Enevoldsen, L. H. Pedersen, N. H. R. Eriksen, F. M. Aarestrup, and N. E. Jensen. 2000. The dynamics of Staphylococcus aureus intramammary infection in nine Danish dairy herds. Vet. Microbiol. 71:89-101.

Matthews, K. R., S. J. Kumar, S. A. O'Conner, R. J. Harmon, J. W. Pankey, L. K. Fox, and S. P. Oliver. 1994. Genomic fingerprints of Staphylococcus aureus of bovine origin by polymerase chain reaction-based DNA fingerprinting. Epidemiol. Infect. 112:177186.

Middleton, J. R., L. K. Fox, and T. H. Smith. 2001. Management strategies to decrease the prevalence of mastitis caused by one strain of Staphylococcus aureus in a dairy herd. J. Am. Vet. Med. Assoc. 218:1615-1618.

Mørk, T., T. Tollersrud, B. Kvitle, H. J. Jørgensen, and S. Waage. 2005. Comparison of Staphylococcus aureus genotypes recovered from cases of bovine, ovine, and caprine mastitis. J. Clin. Microbiol. 43:3979-3984.

Rabello, R. F., C. R. V. M. Souza, R. S. Duarte, R. M. M. Lopes, L. M. Teixeira, and A. C. D. Castro. 2005. Characterization of Staphylococcus aureus isolates recovered from bovine mastitis in Rio de Janeiro, Brazil. J. Dairy Sci. 88:3211-3219.

Raimundo, O., M. Deighton, J. Capstick, and N. Gerraty. 1999. Molecular typing of Staphylococcus aureus of bovine origin by polymorphisms of the coagulase gene. Vet. Microbiol. 66:275-284.

Shimizu, A., H. A. Berkhoff, W. E. Kloos, C. G. George, and D. N. Ballard. 1996. Genomic DNA fingerprinting, using pulsed-field gel electrophoresis, of Staphylocooccus intermedius isolated from dogs. Am. J. Vet. Res. 57:1458-1462.

Smith, T. H., L. K. Fox, and J. R. Middleton. 1998. Outbreak of mastitis caused by one strain of Staphylococcus aureus in a closed dairy herd. J. Am. Vet. Med. Assoc. 212:553-556.

Sommerhäuser, J., B. Kloppert, W. Wolter, M. Zschöck, A. Sobiraj, and K. Failing. 2003. The epidemiology of Staphylococcus aureus infections from subclinical mastitis in dairy cows during a control programme. Vet. Microbiol. 96:91-102.

Tenover, F. C., R. D. Arbeit, R. V. Goering, P. A. Mickelsen, B. E. Murray, D. H. Persing, and B. Swaminathan. 1995. Interpreting chromosomal DNA restriction patterns produced by pulsed-field gel electrophoresis: Criteria for bacterial strain typing. J. Clin. Microbiol. 33:2233-2239.

Zadoks, R., W. van Leeuwen, H. Barkema, O. Sampimon, H. Verbrugh, Y. H. Schukken, and A. van Belkum. 2000. Application of pulsed-field gel electrophoresis and binary typing as tools in veterinary clinical microbiology and molecular epidemiologic analysis of bovine and human Staphylococcus aureus isolates. J. Clin. Microbiol. 38:1931-1939. 